\title{
Moving and looming stimuli capture attention
}

\author{
STEVEN L. FRANCONERI \\ Harvard University, Cambridge, Massachusetts \\ and \\ DANIEL J. SIMONS \\ University of Illinois, Champaign, Illinois
}

\begin{abstract}
Attention capture is often operationally defined as speeded search performance when an otherwise nonpredictive stimulus happens to be the target of a visual search. That is, if a stimulus captures attention, it should be searched with priority even when it is irrelevant to the task. Given this definition, only the abrupt appearance of a new object (see, e.g., Jonides \& Yantis, 1988) and one type of luminance contrast change (Enns, Austen, Di Lollo, Rauschenberger, \& Yantis, 2001) have been shown to strongly capture attention. We show that translating and looming stimuli also capture attention. This phenomenon does not occur for all dynamic events: We also show that receding stimuli do not attract attention. Although the sorts of dynamic events that capture attention do not fit neatly into a single category, we speculate that stimuli that signal potentially behaviorally urgent events are more likely to receive attentional priority.
\end{abstract}

What controls where attention moves? Shifts of visual attention are often classified as either goal directed or stimulus driven (James, 1950/1891). Goal-directed shifts are generated voluntarily and are based on an observer's beliefs about the best place to attend. For example, if an arrow cues the location of an upcoming target, observers can shift attention to that location voluntarily, thereby facilitating target detection relative to trials with no cue or an invalid cue (Posner, Nissen, \& Ogden, 1978). In contrast, stimulus-driven attention shifts are independent of explicit goals and beliefs. We have all experienced this seemingly involuntary capture of our attention: An animal darting across our path, the brightening of brake lights on the car in front of us, and the sudden and maddening appearance of an error message on a computer screen all seem to draw attention regardless of our current task.

In each of these cases, our attention is driven, to some degree, by the stimulus. But to what degree? A variety of experimental tasks have been developed to explore whether stimuli draw attention independently of the observer's beliefs and goals (Folk, Remington, \& Johnston, 1992;

This research was supported by NIH/NIMH Grant R01 MH63773-01 to D.S. D.S. was also supported by a fellowship from the Alfred P. Sloan Foundation, and S.F. was supported by an NDSEG fellowship. Thanks to Melissa Chu, Erin Clifford, Cendri Hutcherson, Matt Kamen, and Julie Schwab for their assistance in data collection. We are also grateful to Patrick Cavanagh, Vince Di Lollo, Chip Folk, Anne Hillstrom, Stephen Mitroff, Steve Most, Ken Nakayama, Robert Rauschenberger, Michael Silverman, Jan Theeuwes, and Jeremy Wolfe for their valuable comments. Correspondence concerning this article should be addressed to S. L. Franconeri, Department of Psychology, Harvard University, 33 Kirkland St., 7th floor, Cambridge, MA 02138 (e-mail: francon@ wjh.harvard.edu) or to D. J. Simons, Psychology Department and Beckman Institute, University of Illinois, 603 E. Daniel St., \#807, Champaign, IL 61820 (e-mail: dsimons@ uiuc.edu).
Theeuwes, 1992; Yantis \& Jonides, 1984). In general, data from all such tasks suggest that no visual stimulus captures attention completely independently of goal-directed processes (Folk et al., 1992; Yantis \& Jonides, 1990). However, previous results from one task-the irrelevant feature search task - do suggest that the abrupt appearance of a new object captures attention in the absence of other competing goals (Yantis, 1996). In fact, evidence from this task has led some to suggest that "the presence of a salient featural singleton in a display is not sufficient to capture attention... . The evidence suggests that a unique abrupt onset is required" (Yantis \& Hillstrom, 1994, p. 96). In contrast to this claim, we report evidence that several types of dynamic events capture attention in the irrelevant feature search task. However, we also show that some dynamic events do not capture in this task, and we speculate about the reasons why some events capture and others do not.

The irrelevant feature search task is designed to explore the types of singleton features that attract attention when the potential influence of top-down goals and search strategies are minimized. To accomplish this, singleton status is assigned to search items randomly so that it does not predict the location of the search target. In a traditional singleton search task, the target always has a singleton feature (e.g., it is the one red item among an otherwise homogeneous set of gray items), and it is found rapidly. However, just because color singletons are found easily does not mean that they capture attention when they do not predict the target location (Yantis \& Egeth, 1999). In the irrelevant feature search task, observers have no reason to purposely ignore the singleton, because it will sometimes be the target item. This task is designed to measure which features attract attention in the absence of competing goals. It does not help to identify singleton features that cannot be ignored. 
The approach to eliminating the influence of the observer's goals has been to define the target by its identity rather than by its status as a singleton, thereby making the singleton feature irrelevant to task performance (Jonides \& Yantis, 1988). In a typical variant of the irrelevant feature search task, subjects determine which of two possible targets (e.g., $\mathrm{U}$ or $\mathrm{H}$ ) is present in a search array. On each trial, one randomly chosen item in the display has a different feature than the others (e.g., it is a color singleton). Observers have no incentive to attend preferentially to the singleton letter, because singleton status does not predict the target's location and is therefore irrelevant to the search. But if the singleton feature captures attention, the singleton will be searched with priority in spite of the fact that it is irrelevant. On most trials, the distinctive item will be a distractor, so search performance will be relatively unaffected (some distractor is likely to be searched first anyway). On some trials, though, the distinctive item will happen to be the target. On such trials, the target will be searched with priority, so search performance should be less influenced by the distractor items. That is, the effect of the number of distractor items should be reduced and search slopes (response time [RT] as a function of the number of items in the search array) should be shallower on trials in which the target happens to be the singleton.

Some experiments using this irrelevant feature search task suggest that observers give processing priority to items that abruptly appear later than other items in the search display (e.g., Yantis \& Jonides, 1984). In these experiments, a variable number of masked letters appear in a circular array. One second later, an additional letter, which is no more likely to be the target than is any other letter, abruptly appears in a previously empty location at the same instant that the previously masked letters are revealed. When the target of the search happens to be the abrupt-onset letter, search slopes are shallower, indicating that the onset letter was given search priority. Strikingly, in studies using this task, few other singleton stimuli have been shown to strongly draw attention. Intuitively, unique or distinctive stimuli (e.g., color singletons) should attract attention, and they are found quickly in traditional singleton search tasks (Treisman \& Gelade, 1980). However, when the target happens to be a color singleton in the irrelevant feature search task, observers are not significantly faster than when the target did not have a unique color (Folk \& Annett, 1994; Jonides \& Yantis, 1988; Theeuwes, 1990; but see Turatto \& Galfano, 2000, 2001). Similarly, neither luminance (Folk \& Annett, 1994) nor motion-defined singletons among static items (Hillstrom \& Yantis, 1994) appear to capture attention. The only other feature that has been previously shown to capture as strongly as an abrupt onset is a sudden change in luminance contrast paired with a change in luminance contrast polarity (Enns, Austen, Di Lollo, Rauschenberger, \& Yantis, 2001). We will address this puzzling exception in the General Discussion section.

Why might onsets capture attention in this task? One possibility is that onsets produce an abrupt luminance change, and it is this transient signal that draws attention. However, most luminance changes apparently are neither necessary nor sufficient to produce capture. Letters that briefly brighten but do not onset fail to capture, and objects that onset without producing a large luminance change (e.g., that appear via texture discontinuity, stereoscopic disparity, or moving noise) still capture (Yantis \& Hillstrom, 1994; but see also Gellatly, Cole, \& Blurton, 1999). An alternative explanation is that abrupt onsets capture because the visual system is sensitive to the appearance of new perceptual objects (Yantis \& Hillstrom, 1994).

Although onsets draw attention even when they are irrelevant, their draw is not completely independent of goaldirected processes. For example, when a target's future location is cued with certainty before a search, onset distractors in other locations do not affect RTs (Yantis \& Jonides, 1990). The fact that onsets can be intentionally ignored implies that they do not draw attention regardless of the observer's goals. Moreover, onsets also fail to capture when other tasks are used, even when they are not actively ignored. For example, in the irrelevant precue search task, subjects search for a red letter among white letters. Immediately prior to the search, one location is cued by an onset, but observers do not give the cued location attentional priority-they are able to ignore the onset precue (Folk et al., 1992). In fact, the effectiveness of a cue in attracting attention seems to depend on the nature of the search task. When one searches for a red target, a red singleton precue draws attention to the cued location. Similarly, if the target is defined by an onset, observers give priority to an onset precue but not to a color precue. Subjects appear to form an "attentional control setting" for the type of target and cannot avoid being captured by the cue when it matches the target (Folk et al., 1992).

In sum, although onsets do not capture independently of goal-directed processes, they do appear to capture when they are irrelevant to a search task. Why, then, are onsets apparently special in the irrelevant feature search task? Perhaps onsets receive additional priority by default unless preempted by other goals, and the irrelevant feature search task exploits this mechanism (Yantis, 1993). Alternatively, onsets might actually be relevant in the irrelevant feature search task: The task itself might induce observers to search for onsets (Folk et al., 1992; B. S. Gibson \& Kelsey, 1998). These two alternatives are discussed in the next sections.

\section{Default Biases}

The first alternative - that observers have a default bias that leads to capture by irrelevant onsets — can be divided into two distinct hypotheses that differ on the basis of how they assign attentional priority. According to the new object hypothesis, abrupt onsets receive priority by default because they indicate the presence of a new perceptual object (Yantis \& Hillstrom, 1994). In the strongest form of this view, only the abrupt appearance of a new object garners attentional priority by default — nothing else is given priority in the absence of competing goals. Why might 
new objects receive processing priority? One possibility is that "the appearance of new objects, and the observer's ability to detect and respond to them, has adaptive significance for visually guided organisms" (Yantis \& Hillstrom, 1994, p. 96). For example, a suddenly appearing object might be animate, and the abrupt appearance of a person or animal might require an immediate response.

According to the dynamic default hypothesis, any dynamic event, and not just abrupt onsets, garners attentional priority by default. Consequently, other types of dynamic events (e.g., strong luminance changes) should capture as well (Folk et al., 1992). ${ }^{1}$ Dynamic events also might be processed quickly because sudden movements could signal important changes in the environment.

\section{Task-Induced Biases}

Although we plausibly might have evolved or learned some default attentional biases, another possibility is that we lack any default attentional priorities: Objects and events capture attention only if they are consistent with our goals. This account attributes capture by onsets in the irrelevant feature search task to the observer's goals. Although the onset itself is statistically irrelevant to the search task, the nature of the task could induce subjects to search for dynamic events, including onsets. In the task, observers monitor the display for the appearance of the search array. This monitoring task creates a goal of searching for dynamic events (i.e., the display appearance). Consequently, abrupt onsets become goal relevant, and capture by onsets can be attributed to the operation of goaldirected processes. By this task-induced bias hypothesis, the irrelevant feature search task does not provide evidence for entirely stimulus-driven capture; the task induces a goal-directed search for onsets (Folk et al., 1992; B. S. Gibson \& Kelsey, 1998).

If this is the case, any feature signaling the start of the search task should also capture. Indeed, if the letters in a search display are red, a red singleton precue captures attention even when it is irrelevant (B. S. Gibson \& Kelsey, 1998). In this case, observers are waiting for the red search display, and the anticipation of this display leads to capture by red singleton precues. In accordance with the predictions of this hypothesis, when the items in the search array are white, a red singleton precue does not capture because observers no longer anticipate a red search array. Although this mechanism might also explain capture by onsets, the original experiments did not test this prediction directly (B. S. Gibson \& Kelsey, 1998, footnote 3; but see Franconeri, Simons, \& Junge, 2003).

In summary, according to two of these accounts, some events capture when no other goals interfere: The new object hypothesis predicts capture by onsets, and the dynamic default hypothesis predicts capture by any dynamic event, including onsets. In contrast, according to the taskinduced bias hypothesis, nothing is automatically given priority. Instead, onsets capture in the irrelevant feature search task because the task itself induces a bias to search for dynamic events. In this view, any dynamic event should capture attention in this task.

\section{Overview of the Experiments}

Findings that most dynamic singletons other than onsets do not strongly capture attention (Enns et al., 2001; Hillstrom \& Yantis, 1994; Theeuwes, 1990; Yantis \& Hillstrom, 1994) support the new object hypothesis over the dynamic default and task-induced default hypotheses. However, in this report, we argue that earlier studies finding no capture by other dynamic events used suboptimal stimuli, and we demonstrate that several kinds of dynamic singletons capture attention as strongly as onsets do. Together with evidence that certain kinds of luminance changes can capture (Enns et al., 2001) and additional evidence for capture by moving stimuli collected concurrently in other labs (Thomas \& Luck, 2000), our results support the idea that abrupt onsets are not unique in their ability to capture attention in the irrelevant feature search task. Furthermore, we report findings that are inconsistent with the predictions of both the dynamic default and the taskinduced capture hypotheses in that not all dynamic singletons capture: Attention capture might be limited to those dynamic events that signal the need for immediate action.

Experiment 1 replicates earlier findings from the irrelevant feature search task by testing for capture by abrupt onsets and color singletons. In Experiments 2 and 3, capture by other dynamic singletons is tested. The new object hypothesis is based on studies that used only abrupt onsets. However, except for the breaking of camouflage, new objects typically do not appear abruptly and all at once. Rather, they are more likely to appear progressively from behind other surfaces (J. J. Gibson, Kaplan, Reynolds, \& Wheeler, 1969). In Experiment 2, a test is conducted of whether new objects that appear via disocclusion from behind another surface capture attention in the irrelevant feature search task. Surprisingly, this type of new object has not been examined in the attention capture literature. All three hypotheses predict that disoccluded objects should be given attentional priority because such objects are both new and dynamic. Experiment 2 also includes a test of capture by a moving object without appearance via disocclusion. The dynamic default and task-induced bias hypotheses both predict that such moving objects should capture, but the new object hypothesis predicts that they should not.

In Experiment 3, further predictions of the dynamic default and task-induced bias hypotheses are tested. According to both accounts, any dynamic event should capture attention. We find, however, that some dynamic events do not capture attention, and we propose a new hypothesis to account for these results.

\section{EXPERIMENT 1 Onsets and Color Singletons}

In the irrelevant feature search task, the abrupt onset of a new object captures attention, but the presence of a color singleton does not (Folk \& Annett, 1994; Jonides \& Yantis, 1988; Theeuwes, 1990). In Experiment 1, we attempted to replicate these findings. These displays are then adapted in subsequent experiments to explore capture by other dynamic events. 


\section{Method}

Subjects. Thirty-two Harvard University undergraduates (16 in the onset condition and 16 in the color condition) voluntarily participated in the study in exchange for $\$ 7$ or class credit. The study lasted approximately $35 \mathrm{~min}$.

Stimuli. The stimuli were created and presented using the VisionShell C libraries (http://www.kagi.com/visionshell) on an Apple iMac 15-in. CRT monitor. Head position was unrestrained, but viewing distance averaged approximately $50 \mathrm{~cm}$. From this distance, the display subtended $31.28^{\circ}$ in width $\times 23.46^{\circ}$ in height and consisted of a black background $\left(0.5 \mathrm{~cd} / \mathrm{m}^{2}\right)$, a light gray fixation point $\left(37 \mathrm{~cd} / \mathrm{m}^{2}\right)$, and a variable number of gray letters $\left(27 \mathrm{~cd} / \mathrm{m}^{2}\right)$. In the color condition, one of the letters was red $\left(27 \mathrm{~cd} / \mathrm{m}^{2}\right)$. The letters were arranged on an imaginary circle around the fixation point at an eccentricity of $4.5^{\circ}$. Letter line segments were 1 pixel wide, and each letter was $2^{\circ}$ in width and height. The letters were of the block type used in digital clocks (seven possible segments) so that any letter could be obtained by subtracting line segments from a block 8 . Possible letters were E, P, S, C, F, L, H, and U. Each display contained three, five, or seven letters in the final search display. In both the color and onset conditions, the final search display contained either a $\mathrm{U}$ or an $\mathrm{H}$, and the subjects responded by pressing the corresponding key on the keyboard to indicate which was in the display. Of the total of 426 trials, 90 contained three letters, 140 contained five letters, and 196 contained seven letters. Each letter position in a display was equally likely to contain the target. For displays containing $N$ letters, the target letter was unique (i.e., an onset or a color singleton) on $1 / N$ trials. Consequently, the location of the unique item was not predictive of the target location. Figures 1A and 1B depict the displays in both conditions.

Procedure. The subjects pressed a key to begin a trial. In the onset condition, a fixation point appeared, and after $300 \mathrm{msec}$, two, four, or six figure $8 \mathrm{~s}$ appeared. Because one letter was missing from the final search array, these figure $8 \mathrm{~s}$ served as placeholder masks so that the subjects could not begin their search until all the letters had been presented. After 1,000 msec, all masks were removed at the same instant that the missing letter appeared (see Figure 1A). In the color condition, no masks were shown. The fixation point appeared, and after $1,000 \mathrm{msec}$ a search display containing one red letter was presented (see Figure 1B). In both conditions, the search display remained visible until the observers responded by pressing the $\mathrm{H}$ key or the U key to indicate which letter had been present.

The experimenter explained that late appearing or uniquely colored objects were not more likely to be the target. The subjects were given 25 practice trials, and both speed and accuracy were stressed. The subjects were invited to take a break after any trial.

\section{Results and Discussion}

Eliminating outliers and errors. In this and both of the following experiments, trials with RTs longer than $3 \mathrm{sec}$ were counted as errors. Data from an additional 2 subjects in the onset condition were eliminated from the analysis because their error rates were greater than $10 \%$. For the remaining subjects, RT outliers were removed from the analysis. Trials with RTs \pm 2 standard deviations ( $S D \mathrm{~s})$ from the mean for an individual subject's combination of set size and target type were removed, and one trial with an RT on the opposite side of the distribution was eliminated as well (Rosenthal \& Rosnow, 1991). Nine percent of the responses in the color condition and $10 \%$ of those in the onset condition were eliminated because they were RT outliers according to this criterion. For this and both of the other experiments, slopes derived from these trimmed means were almost identical to those obtained by trimming trials with RTs that were more than $3 S D$ s from the mean (this more liberal inclusion criterion eliminates $2 \%-3 \%$ of the RT data on average).

Assessing attention capture. Search priority can be measured by comparing the search slope on trials when the cue happened to be the target (valid) to the search slope when the cue happened to be a distractor (invalid). Because shallower slopes reflect more efficient processing, a significantly shallower slope on valid than on invalid trials implies that the cued item received attentional priority over uncued items. Reliable slope differences can be tested either through a $t$ test on mean slopes for the valid and invalid cue trials or by examining the interaction between set size and cue type in an analysis of variance (ANOVA). Both measures closely agree in all of our experimental conditions; for clarity of exposition, we report the $t$-test results in the text and in Figure 1, and for completeness, we also report the ANOVA results in Table 1. Although a difference between valid and invalid slopes suggests some degree of prioritization, a stronger criterion for attention capture is that valid slopes are essentially flat. A slope of zero suggests that cued items fully captured attention on almost all trials. This criterion is usually fulfilled when the $95 \%$ confidence interval for a valid slope includes zero (Yantis \& Jonides, 1984). For each condition, we also report this confidence interval.

Although the fact is typically not discussed in the literature, many studies using the irrelevant feature search task do not exhibit linear slopes. Slopes are often flat at small set sizes but steeper at larger set sizes. ${ }^{2}$ Those researchers who found flat search slopes for abrupt-onset letters on valid trials (under $10 \mathrm{msec} / \mathrm{item}$, where zero is usually within the slope's 95\% confidence interval; Jonides \& Yantis, 1988; Miller, 1989; Yantis \& Jonides, 1984) all used only small set sizes (two and four items). In general, even for abrupt onsets, valid slopes appear to increase with set size. For example, with set sizes of three and six items, in one study a valid slope of $7 \mathrm{msec} /$ item was found (Enns et al., 2001), and in another a slope of $12 \mathrm{msec} /$ item was found (Thomas \& Luck, 2000). With set sizes 3 and 7, valid slopes of $15 \mathrm{msec} /$ item were found in Gellatly et al. (1999), and we found slopes of $22 \mathrm{msec} /$ item (our Experiment 1).

In many of these studies, it is difficult to assess whether capture effects attenuate with an increasing number of items in the display, because the studies include only two set sizes. In the few onset studies in which more than two set sizes are tested, capture effects disappear at set sizes larger than 5 (Jonides \& Yantis, 1988; Martin-Emerson \& Kramer, 1997). For example, in one study onset target slopes were flat between set sizes of 3 and 5 items, but capture effects completely disappeared between set sizes of 5 and 7 items (Jonides \& Yantis, 1988). In another study, onset target slopes were $11 \mathrm{msec} /$ item from 3 to 5 items but became statistically indistinguishable from the non-onset target slopes (24 msec/item) for set sizes of 5-7 and 7-13 items (Martin-Emerson \& Kramer, 1997). 


\begin{tabular}{|c|c|c|c|c|c|}
\hline & $1,000 \mathrm{msec}$ & $150 \mathrm{msec}$ & Search & Results & \\
\hline $\begin{array}{l}\text { A) Onset } \\
\text { (Experiment 1) }\end{array}$ & $\mathrm{B}_{\mathrm{B}}^{\mathrm{B}} \mathrm{B}$ & (none) & & 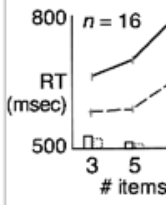 & \begin{tabular}{l|rll} 
slope & $3-5$ & $5-7$ & $3-7$ \\
valid & 3 & 36 & 19 \\
invalid & 18 & 48 & 33 \\
Ialid $C l$ & 17 & 25 & 10 \\
$S^{\prime \prime} S<<$ & $63 \%$ & $69 \%$ & $75 \%$ \\
$t(115)$ & 1.7 & 0.9 & 2.4 \\
$p<=$ & .11 & .39 & .03
\end{tabular} \\
\hline $\begin{array}{l}\text { B) Color } \\
\text { singleton } \\
\text { (Experiment 1) }\end{array}$ & (none) & (none) & & 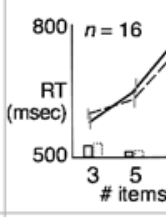 & 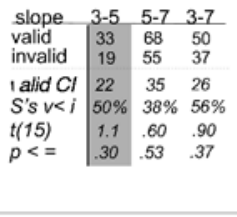 \\
\hline $\begin{array}{l}\text { C) Disocclusion } \\
\text { (Experiment 2) }\end{array}$ & & & & $\begin{array}{r}800 \\
\mathrm{RT} \\
(\mathrm{msec}) \\
500\end{array}$ & \begin{tabular}{l|lll} 
slope & $3-5$ & $5-7$ & $3-7$ \\
valid & -1 & 29 & 14 \\
invalid & 18 & 66 & 42 \\
Ialid $C l$ & 12 & 16 & 10 \\
S's $<<i$ & $75 \%$ & $94 \%$ & $100 \%$ \\
$t(f(1))$ & 2.7 & 4.2 & 5.0 \\
$\rho<=$ & .02 & .01 & .01 \\
& & &
\end{tabular} \\
\hline $\begin{array}{l}\text { D) Motion over } \\
\text { occluder } \\
\text { (Experiment 2) }\end{array}$ & & & & 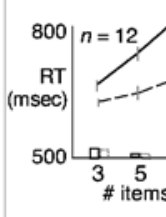 & \begin{tabular}{l|ccc} 
slope & $3-5$ & $5-7$ & $3-7$ \\
valid & 7 & 22 & 15 \\
invalid & 32 & 62 & 47 \\
'alid $C l$ & 16 & 10 & 9 \\
$S ' s<<i$ & $83 \%$ & $92 \%$ & $100 \%$ \\
$t(11)$ & 2.7 & 5.0 & 5.1 \\
$\rho<=$ & .02 & .01 & .01 \\
& & &
\end{tabular} \\
\hline $\begin{array}{l}\text { E) Motion } \\
\text { without } \\
\text { occluder } \\
\text { (Experiment 2) }\end{array}$ & $\begin{array}{c}\mathrm{\theta} \\
\mathrm{B} \\
\mathrm{B}\end{array}$ & 日 & & \begin{tabular}{r|r}
800 & $n=1$ \\
$\mathrm{RT}$ & \\
(msec) & \\
500 & $\frac{n}{3}$ \\
&
\end{tabular} & \begin{tabular}{l|lll} 
slope & $3-5$ & $5-7$ & $3-7$ \\
valid & 11 & 22 & 17 \\
invalid & 28 & 55 & 42 \\
Ialid $C l$ & 22 & 10 & 10 \\
$S^{\prime} s<v<i$ & $69 \%$ & $92 \%$ & $92 \%$ \\
$t^{\prime}(12)$ & 1.4 & 4.7 & 4.1 \\
$p<=$ & .18 & .01 & .01
\end{tabular} \\
\hline $\begin{array}{l}\text { F) Jitter motion } \\
\text { (Experiment 2) }\end{array}$ & $\underset{\theta}{\mathrm{\theta}}$ & ${ }^{8}{ }^{8}$ & $\begin{array}{c}5 \cdot \mathrm{H} \\
\mathrm{E} P\end{array}$ & $\left.\begin{array}{r}\mathrm{RT} \\
(\mathrm{msec})\end{array}\right]$ & \begin{tabular}{l|lll} 
slope & $3-5$ & $5-7$ & $3-7$ \\
valid & 9 & 18 & 14 \\
invalid & 27 & 34 & 31 \\
lalid $C l$ & 13 & 13 & 1 \\
S's $<<$ & $80 \%$ & $87 \%$ & $80 \%$ \\
$t(14)$ & 2.4 & 1.9 & 2.6 \\
$p<=$ & .03 & .07 & .02
\end{tabular} \\
\hline $\begin{array}{l}\text { G) Looming } \\
\text { (Experiment 3) }\end{array}$ & ${ }_{\theta}^{8}{ }_{\theta}^{8}$ & 日昌 & $\begin{array}{c}\mathrm{S}_{\mathrm{E}}^{\mathrm{C}} \mathrm{P} \\
\mathrm{E}\end{array}$ & 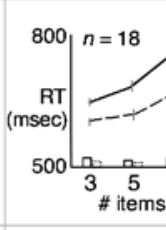 & \begin{tabular}{l|lll} 
slope & $3-5$ & $5-7$ & $3-7$ \\
valid & 7 & 56 & 17 \\
invalid & 25 & 61 & 43 \\
ialid $C l$ & 13 & 11 & 7 \\
$S^{\prime} s v<i$ & $78 \%$ & $83 \%$ & $94 \%$ \\
$t(17)$ & 2.2 & 3.8 & 4.77 \\
$\rho<=$ & .04 & .01 & .01
\end{tabular} \\
\hline $\begin{array}{l}\text { H) Receding } \\
\text { (Experiment 3) }\end{array}$ & ${ }_{\mathrm{B}}^{\mathrm{B}} \stackrel{\mathrm{B}}{\mathrm{B}}$ & $\rightarrow{ }^{\mathrm{\theta}} \stackrel{\mathrm{\theta}}{\mathrm{\theta}}$ & ${ }_{E}^{5} \cdot \mathrm{H}$ & 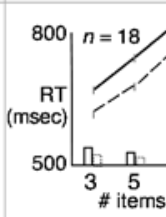 & 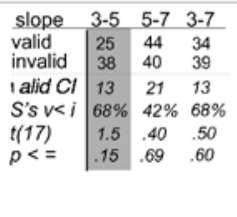 \\
\hline
\end{tabular}

Figure 1. Displays, average search slopes, and statistical tests for Experiments 1, 2, and 3. Error bars represent standard errors. In the statistical calculations, the first two rows give valid and invalid cue trial search slopes at each set size interval. The next row lists $95 \%$ confidence intervals (CIs) for valid slopes in each set size range. A property captures attention if zero is within a valid slope's CI. The fourth row gives the percentage of subjects (S's) in each set size range that show valid slopes lower than invalid slopes. Displays are not drawn to scale. $v=$ valid trials in which the target has the irrelevant feature; $i=$ invalid trials in which a distractor has the irrelevant feature. 
Table 1

Analyses of Variance for Experiments 1-3

\begin{tabular}{|c|c|c|c|c|c|c|c|}
\hline & \multicolumn{3}{|c|}{ Cue (Valid/Invalid) } & \multicolumn{2}{|c|}{ Set Size } & \multicolumn{2}{|c|}{ Cue $\times$ Set } \\
\hline & $N$ & $F$ & $p \leq$ & $F$ & $p \leq$ & $F$ & $p \leq$ \\
\hline \multicolumn{8}{|c|}{ Slopes 3-5 } \\
\hline Onset & 15 & 135.5 & .001 & 4.1 & .060 & 3.4 & .090 \\
\hline Color & 15 & 0.02 & .890 & 12.6 & .003 & 1.8 & .200 \\
\hline Disocclusion & 15 & 28 & .001 & 5 & .040 & 6.8 & .020 \\
\hline Motion over occlusion & 11 & 12 & .006 & 14 & .003 & 7.0 & .020 \\
\hline Motion, no occlusion & 12 & 8.8 & .010 & 8 & .020 & 2.7 & .130 \\
\hline Jitter motion & 14 & 21 & .001 & 15 & .002 & 9.2 & .010 \\
\hline Loom & 17 & 62 & .001 & 10 & .006 & 11 & .004 \\
\hline Recede & 18 & 27 & .001 & 29 & .001 & 6.0 & .030 \\
\hline \multicolumn{8}{|c|}{ Slopes 3-7 } \\
\hline Onset & 15 & 107 & .001 & 34 & .001 & 3.8 & .030 \\
\hline Color & 15 & 0.2 & .700 & 29 & .001 & 1.0 & .370 \\
\hline Disocclusion & 15 & 40 & .001 & 48 & .001 & 27 & .001 \\
\hline Motion over occlusion & 11 & 21 & .001 & 42 & .001 & 25 & .001 \\
\hline Motion, no occlusion & 12 & 19 & .001 & 41 & .001 & 13 & .001 \\
\hline Jitter motion & 14 & 44 & .001 & 25 & .001 & 9.4 & .001 \\
\hline Loom & 17 & 77 & .001 & 66 & .001 & 15 & .001 \\
\hline Recede & 18 & 22 & .001 & 39 & .001 & 1.7 & .200 \\
\hline \multicolumn{8}{|c|}{ Error Rate $(3,5,7)$} \\
\hline Onset & 15 & 5.9 & .030 & 3.7 & .040 & 0.1 & .870 \\
\hline Color & 15 & 2.3 & .150 & 6.4 & .005 & 0.3 & .760 \\
\hline Disocclusion & 15 & 5.8 & .030 & 3.3 & .050 & 1.0 & .380 \\
\hline Motion over occlusion & 11 & 1.7 & .210 & 3.1 & .070 & 1.5 & .240 \\
\hline Motion, no occlusion & 12 & 7.6 & .020 & 1.6 & .220 & 4.1 & .030 \\
\hline Jitter motion & 14 & 0.8 & .390 & 3.9 & .040 & 0.4 & .650 \\
\hline Loom & 17 & 6.9 & .020 & 2.0 & .150 & 0.2 & .830 \\
\hline Recede & 18 & 15 & .001 & 9.0 & .001 & 1.0 & .370 \\
\hline
\end{tabular}

Note-For the Slope 3-5 analysis, the $F$ values are based on one degree of freedom $(d f)$ in the numerator and either $N-1 d f$ (cue analysis) or $2(N-1) d f$ (set size and cue $\times$ set analyses) in the denominator. For the Slope 3-7 and error rate analyses, the $F$ values are based on $1 d f$ in the numerator and $N-1 d f$ in the denominator (cue analysis) or $2 d f$ in the numerator and $2(N-1) d f$ in the denominator (set size and cue $\times$ set analyses).

Why do capture effects disappear at set sizes larger than 5 ? One possibility is that as set size increases, so does the number of offset transients created by the removal of letter masks. With a large enough set size, this transient noise begins to overpower the transient created by the onset (Gellatly et al., 1999; Martin-Emerson \& Kramer, 1997; Thomas \& Luck, 2000). In accordance with this explanation, adding additional segments to letter masks (which creates larger offset transients) severely attenuates capture effects at all set sizes (Martin-Emerson \& Kramer, 1997; Miller, 1989).

Although we included set sizes 3, 5, and 7 in our capture studies, evidence from the literature suggests that set sizes larger than 5 do not provide a clear test of capture in the irrelevant feature search task. We report slopes for both small and large set sizes in Figure 1 and provide statistical analyses for all set sizes in Table 1, but our primary analyses and conclusions are based on the slopes for three to five items.

Evidence from color and onsets. Figures 1A and 1B show mean RTs, slopes, and error rates for the onset and color conditions, respectively. In the onset condition, search slopes for three to five items were shallower when the target happened to be the abruptly appearing letter
$(M=3 \mathrm{msec} /$ item $)$ than when it was a distractor $(M=$ $18 \mathrm{msec} /$ item). Although the valid cue slope (but not the invalid cue slope) had zero within its $95 \%$ confidence interval $(\mathrm{CI}= \pm 17 \mathrm{msec} /$ item $)$, the difference between the valid and the invalid slopes only approached significance $[t(15)=1.7, p=.11$; all statistical comparisons in this and subsequent experiments were two-tailed unless otherwise noted]. This lack of a significant difference most likely resulted from the high variance among the valid slopes $(S D=34 \mathrm{msec})$. However, the slopes are identical to those found by other labs. For example, a similar study in which set sizes 2 and 4 were used showed a valid slope of $7 \mathrm{msec} /$ item and an invalid slope of $14 \mathrm{msec} /$ item, and although zero was within the $95 \%$ confidence interval of the valid slope (but not the invalid slope), the difference between the slopes was not statistically different at the $p<$ .05 level (Yantis \& Jonides, 1984). Thus, the results of our onset condition replicate the standard finding of attention capture.

As was expected, in the color condition search slopes were not significantly different when a color singleton happened to be the target $(M=33 \mathrm{msec} / \mathrm{item})$ than when it was a distractor $[M=19$ msec/item, $t(15)=1.1, p=$ .30]. This finding replicates evidence that color singletons 
do not strongly capture attention in the irrelevant feature search task (Folk \& Annett, 1994; Jonides \& Yantis, 1988; Theeuwes, 1990; Todd \& Kramer, 1994; Yantis \& Egeth, 1999; but see Turatto \& Galfano, 2000, 2001).

We must ensure that speed-accuracy tradeoffs are not responsible for differences between valid and invalid slopes or for shallow valid slopes. If differences between valid and invalid slopes were caused by differences in accuracy, then error rates should show an interaction between set size and cue type. Neither the onset $[F(2,30)=$ $0.1, p=.87]$ nor the color $[F(2,30)=0.3, p=.76]$ condition shows this interaction among all three set sizes. For the flat valid slope test, if a speed-accuracy tradeoff caused a slope between three and five items to be artificially flat, we should find a higher error rate for five items than for three items. On the contrary, for both onset and color conditions, error rates decreased from three to five items. Although this result validates the flat slopes in the onset condition, it could be the cause of the nonflat slopes in the color condition. However, given that valid slopes in the color condition were actually (but nonsignificantly) steeper than invalid slopes and the differences in error rates between set sizes 3 and 5 for valid trials was small $(2.6 \%)$, a speed-accuracy tradeoff probably cannot explain the lack of capture by a color singleton.

These results replicate past findings that abrupt onsets receive processing priority (Jonides \& Yantis, 1988; Yantis \& Jonides, 1984), but color singletons do not (Folk \& Annett, 1994; Jonides \& Yantis, 1988; Theeuwes, 1990; Todd \& Kramer, 1994; Yantis \& Egeth, 1999), thereby validating our methods and displays - findings of capture in the remaining experiments are not likely to be due to differences between our displays and procedures and those used in other studies with the irrelevant feature search task.

\section{EXPERIMENT 2 Disocclusion and Motion}

In natural scenes, new objects rarely appear abruptly; they are more likely to appear by progressive disocclusion from behind other surfaces (J. J. Gibson et al., 1969). Surprisingly, this manner of new object appearance has not been tested in any of the standard capture paradigms. The new object hypothesis predicts that this event should capture because gradually appearing objects are new to the display. Both the dynamic default and the task-induced bias hypotheses also predict capture by a disoccluded object, because disocclusion is a dynamic event. These hypotheses make contrasting predictions for an object that moves but that is not new to the display. The new object hypothesis predicts that motion alone should not capture, because moving objects are not new. Both the dynamic default and the task-induced bias hypotheses, however, predict that moving objects should capture because they are both dynamic events.

Experiment 2 includes a disocclusion condition and three motion conditions. In the disocclusion condition, a hidden letter quickly moves from beneath an occluder to join the search display. The motion-over-occluder condition is identical, except that the letter is always visible because it appears on top of the occluder. In the motion-withoutoccluder condition, the motion is the same, but the occluder is never present. The jitter motion condition allows for a test of oscillatory motion over a small spatial distance. In each condition, all moving and nonmoving letters are masked until the end of the motion phase, when the search items are revealed.

Although some previous work indicates that moving singletons do not strongly capture attention (Hillstrom \& Yantis, 1994), these studies used displays that might have been insufficient to produce strong capture. For example, Hillstrom and Yantis used five types of motion: (1) streaming texture inside a letter, (2) dots revolving around a letter, (3) scintillating random dot texture inside a letter, (4) horizontal oscillation of a letter's position $\left(0.5^{\circ}\right)$, and (5) oscillatory looming and receding consisting of a two-frame animation alternating a large version of a letter with a smaller version. Three features of these displays could contribute to the weak capture effects observed. First, the motion continued throughout the search, and moving letters might be more difficult to identify. If so, subjects might purposely search other letters first. Second, each type of motion began at the same time as the offsets of the letter masks, when the number of screen transients were at their maximum. The motion signal from the start of the object's motion may have been lost in the transient noise created by the letter offsets, thus reducing the moving item's ability to draw attention (Thomas \& Luck, 2000). In contrast, the motion in our displays always began $150 \mathrm{msec}$ before the masks were removed, and the stimuli were no longer moving during the search itself. Third, the letters either never changed spatial position (Conditions A, B, and C) or moved only over a short distance (Conditions D and E) perhaps a large change in spatial location is necessary for motion to induce capture. If so, we expect capture in the motion-over-occluder and motion-without-occluder conditions, but not in the jitter motion condition.

\section{Method}

Subjects. Fifty-two Harvard University undergraduates (15 in the disocclusion condition, 11 in the motion-over-occluder condition, 12 in the motion-without-occluder condition, and 14 in the jitter motion condition) were either paid $\$ 7$ or given class credit for their participation. Data from an additional subject were removed from the jitter motion condition because of high error rates.

Materials and Procedure. Except as noted, timing and displays were identical to those of the onset condition of Experiment 1. The subjects pressed a key to begin each trial. In the disocclusion condition (Figure 1C), a fixation point appeared for $200 \mathrm{msec}$ and was followed by a masked search display. A doughnut-shaped occluder encircled the masked letters so that all of these letters were surrounded by the inner edge of the occluder. The inner and outer edges of this occluder were 1 pixel wide and were $6.20^{\circ}$ and $8.95^{\circ}$ from fixation, respectively. One of the masked letters was missing, hidden behind the occluder. After 1,000 msec, the missing letter moved inward from underneath the occluder to match the eccentricity of the other items $\left(4.5^{\circ}\right)$ over the course of $150 \mathrm{msec}$. The animation (18 frames) appeared as smooth motion. The motion-over-occluder 
condition (Figure 1D) was identical to the disocclusion condition except that when the masked display appeared, one letter was in front of rather than behind the occluder. After 1,000 msec, it moved to match the eccentricity of the other items using the same animation as in the disocclusion condition. The motion-without-occluder condition (Figure 1E) was identical except that the occluder was never present. In the jitter motion condition (Figure 1F), one masked letter started at an eccentricity of $0.6^{\circ}$ farther from center than the other letters. Over the course of $150 \mathrm{msec}$, the letter moved $0.6^{\circ}$ toward and away from fixation five times, finally stopping at the same eccentricity as the other letters. The total distance covered by the moving letter during the oscillation was the same as in the other two motion conditions. In all conditions, masks were immediately removed upon completion of the motion, and the subjects began their search. The experimenter explained to the subjects that disoccluded or moved objects were no more likely to be the target than were any of the other display items.

\section{Results and Discussion}

For each subject in all conditions, RT outliers were removed by the method described in Experiment 1 (10\% in the disocclusion condition, $9 \%$ in the motion-over-occluder condition, $9 \%$ in the motion-without-occluder condition, and $9 \%$ in the jitter motion condition). Figures $1 \mathrm{C}-1 \mathrm{~F}$ show the mean RTs and error rates as a function of set size and cue type. Valid slopes in the disocclusion condition were significantly shallower $(M=-1 \mathrm{msec} /$ item $)$ than the invalid slopes $[M=18 \mathrm{msec} / \mathrm{item} ; t(15)=2.7, p<.02]$. Search was also more efficient when the moving letter in the motion-over-occluder condition happened to be the target $(M=7 \mathrm{msec} / \mathrm{item})$ than when it was not $[M=$ $32 \mathrm{msec} /$ item; $t(11)=2.7, p=.02$ ]. In the motion-withoutoccluder condition, although valid slopes $(M=11 \mathrm{msec} /$ item) were also shallower than invalid slopes $(M=28 \mathrm{msec} /$ item), this difference only approached significance $[t(12)=1.4, p=.18]$. This lack of significance appears to be due to a single subject with a valid slope of $117 \mathrm{msec} /$ item, which is $3 S D$ s above the mean and 2.6 times larger than the next steepest slope. When data from this outlier subject were removed, valid slopes $(M=2 \mathrm{msec} / \mathrm{item})$ were significantly shallower than invalid slopes $[M=$ $25 \mathrm{msec} /$ item; $t(11)=2.9, p<.02$ ]. Finally, in the jitter motion condition valid slopes $(M=9 \mathrm{msec} / \mathrm{item})$ were shallower than invalid slopes [27 msec/item; $t(14)=2.4$, $p=.03]$. Each condition's valid slopes contain zero within their $95 \%$ confidence interval, but their invalid slopes do not (see Figures 1C-1F for confidence intervals).

In all conditions, error rates declined as set size increased from three to five items, so shallow valid slopes cannot be explained by a speed-accuracy tradeoff. In most cases, interactions between set size and cue type were not statistically reliable. The motion-without-occluder condition was an exception $[F(2,24)=4.1, p=.03]$. The significant interaction reflects a slightly higher error rate for invalid trials of set size 3 , which could have artificially lowered the RTs on those trials. If this is the case, the result would be a slightly steeper slope on invalid trials. However, this higher error rate for invalid trials of set size 3 largely reflects the data of 3 subjects. Excluding the data of these 3 subjects eliminated the significant set size $\times$ cue type interaction in accuracy but left the slopes virtually unchanged. Even if the results from the motion-withoutoccluder condition are equivocal due to this possible speedaccuracy tradeoff, the other two motion conditions show unambiguous capture by moving objects.

In accordance with the new object, dynamic default, and induced capture hypotheses, an object that appeared via disocclusion captured attention. Abrupt onsets are not necessary for a new object to capture attention. However, moving objects also captured attention, a finding that is inconsistent with the predictions of the new object hypothesis but consistent with the predictions of both the dynamic default and the task-induced bias hypotheses. When an object suddenly moves to a different spatial position, it captures as strongly as an abrupt onset. Similar results obtained concurrently by another lab confirm that moving singletons capture attention as strongly as abrupt onsets (Thomas \& Luck, 2000). The difference in results between this experiment and previous work (Hillstrom \& Yantis, 1994) was most likely due to differences in the way in which the critical feature was presented. In past work, one item began moving when the letter masks offset and continued moving as the observer searched the display. In this procedure, the start of the motion might have been masked by the simultaneous offset transients as the other letters were unmasked (Thomas \& Luck, 2000; see also Gellatly et al., 1999; Martin-Emerson \& Kramer, 1997; Miller, 1989). Furthermore, the continuing motion during the search might have made identification of the moving letter more difficult. In contrast, the motion cues in our experiment lasted for $150 \mathrm{msec}$ and ended before the letter masks were removed.

\section{EXPERIMENT 3 Looming and Receding}

Experiment 2 showed that dynamic singletons other than abrupt onsets capture attention in the irrelevant feature search task. Do they capture because default attentional priority is assigned to dynamic singletons (dynamic default hypothesis) or because the irrelevant feature search task requires subjects to search for dynamic singletons (task-induced bias hypothesis)? Each of these accounts is consistent with the results of Experiments 1 and 2. Both predict that any dynamic event should produce capture in the irrelevant feature search task. In Experiment 3, these predictions were tested by exploring capture by different types of motion. Recall that the new object and dynamic default hypotheses were intuitively plausible, because onsets and other dynamic events could signal behaviorally urgent events. However, some dynamic events might be more behaviorally urgent than others. According to our behavioral urgency hypothesis, only stimuli that signal an event that could require urgent action receive processing priority in the absence of competing goals. Whereas the dynamic default and task-induced bias hypotheses predict 
capture by any dynamic singleton, the behavioral urgency hypothesis predicts capture only by events that might signify the need for urgent action.

Testing contrasting predictions of these views requires examining the capture strength of two stimuli of equal magnitude as dynamic events, but with differences in their behavioral urgency. To this end, we looked for capture by looming and receding objects. Looming objects might indicate an impending collision or an approaching object. Behavioral evidence supports the potential urgency of looming stimuli; for example, infants show a fear response (see, e.g., Náñez, 1988) and insects show a hiding response (see, e.g., Hassenstein \& Hustert, 1999) on viewing expanding patterns that simulate a looming object (see also Wang \& Frost, 1992). If capture is driven by behavioral urgency, then a looming object should capture. ${ }^{3}$ In contrast, a receding object is not as behaviorally urgent, so it should capture only weakly or not at all.

In Experiment 3, one letter started out smaller or larger than the rest and grew or shrank to the same size as the nonsingleton letters. Looming letters grew from $1.55^{\circ}$ to $2.3^{\circ}$ (a $48 \%$ change), and receding letters shrank from $4.6^{\circ}$ to $2.7^{\circ}$ (a $41 \%$ change). The letters in the final search displays were slightly larger in the receding condition than in the looming condition. ${ }^{4}$ Although the percent changes were approximately equal between the two conditions, the raw size change in terms of object diameter was much larger for the receding $\left(1.9^{\circ}\right)$ than for the looming $\left(0.75^{\circ}\right)$ condition. If looming still captures attention whereas receding does not, it could not be because looming features underwent a larger change.

\section{Method}

Subjects. Thirty-seven Harvard University undergraduates (18 in the looming condition and 19 in the receding condition) were either paid $\$ 7$ or given class credit for their participation. Data from 1 additional subject in the looming condition and 3 additional subjects in the receding condition were removed from the analysis because of high error rates.

Materials and Procedure. Except as noted, timing and displays were identical to those of the motion-without-occluder condition of Experiment 2. On each trial, a fixation point appeared, followed after $300 \mathrm{msec}$ by three, five, or seven masked letters. Because all parts of a looming or receding object grow or shrink as the whole object's size changes, we used letters with segments made of thick bars instead of thin lines. Horizontal segments were always $20 \%$ as tall and vertical segments were always $33 \%$ as wide as the letter's current size, so that as the letter grew or shrank, the letter segments grew or shrank proportionally. After $1,000 \mathrm{msec}$, one masked letter either grew or shrank to the same size as the other letters in the display over $150 \mathrm{msec}$. In the looming condition (Figure 1G), one masked letter was initially smaller than the rest and then grew to be the same size as the other items $\left(1.55^{\circ}\right.$ to $\left.2.3^{\circ}\right)$. In the receding condition (Figure $1 \mathrm{H}$ ), one masked letter was larger than the rest and then shrank $\left(4.6^{\circ}\right.$ to $\left.2.7^{\circ}\right)$. Masks were removed immediately after the animation, and the subjects began their search.

\section{Results and Discussion}

Through the outlier removal procedure described in Experiment $1,9 \%$ of trials in the looming condition and $9 \%$ in the receding condition were eliminated. Figures $1 \mathrm{G}$ and
$1 \mathrm{H}$ show the mean RTs and error rates as a function of set size and target type. Search slopes were significantly shallower for valid $(M=7 \mathrm{msec} /$ item $)$ than for invalid $(M=$ $25 \mathrm{msec} /$ item) looming trials $[t(17)=2.2, p=.04]$. The valid slope for the looming condition had zero within its $95 \%$ confidence interval, but the invalid slope did not. Although receding objects did receive some search priority, the difference between valid $(M=25 \mathrm{msec} /$ item $)$ and invalid $(M=38 \mathrm{msec} /$ item $)$ slopes was much smaller and not statistically reliable $[t(18)=1.5, p=.15]$, although it was significant according to the set size $\times$ cue type interaction in an ANOVA of only set sizes 3 and $5[F(1,18)=$ $6, p=.03]$. The valid slope did not contain zero in its confidence interval. A planned one-tailed test revealed a significant difference between valid slopes in the looming and receding conditions $[t(35)=2.14, p=.039]$.

This difference between looming and receding objects is inconsistent with the new object hypothesis-looming objects captured even though they were not new objects. Although the dynamic default and task-induced bias hypotheses correctly predicted that a looming object would capture, they incorrectly predicted that receding objects would capture equally well. Thus, this pattern of results is inconsistent with the three primary explanations of attention capture by abrupt onsets proposed in the literature. However, it is consistent with the behavioral urgency hypothesis-looming objects are behaviorally urgent, whereas receding objects are not.

The asymmetry between looming and receding remained strong even though the looming stimulus underwent a larger diameter change than the receding stimulus. However, in some respects, the looming stimulus might still be a stronger dynamic signal. For example, observers can detect the presence or absence of expanding luminance gratings among contracting gratings more efficiently than they can detect contracting gratings among expanding gratings (Takeuchi, 1997). This asymmetry suggests that, at a low level of processing, expanding stimuli might represent a larger dynamic signal in the visual system. However, expanding stimuli might also be found more rapidly because they attract attention.

\section{GENERAL DISCUSSION}

Across three experiments, some but not all dynamic events capture attention in the irrelevant feature search task. Experiment 1 replicated past results indicating that abrupt onsets, but not color singletons, capture attention in the irrelevant feature search task. Experiment 2 showed that onsets are not unique in this respect, because disoccluding and moving objects capture as well. Experiment 3 showed that not all dynamic singletons capture: Although looming objects strongly capture, receding objects do not. Together, these results are inconsistent with three major accounts of what captures attention. The new object hypothesis states that only new objects should capture in the irrelevant feature search task. The dynamic default hypothesis states that any dynamic singleton (including new 
objects) should capture. The task-induced bias hypothesis states that stimuli capture in the irrelevant feature search task because the task induces subjects to search for dynamic events (e.g., the appearance of the search display). We find that many dynamic events capture attention, so new objects are not unique. Furthermore, both the dynamic default and the task-induced bias hypotheses predict that any dynamic singleton should capture, but receding objects do not.

Here we propose an alternative derived from the original rationale for why onsets capture attention: The abrupt appearance of a new object might have behavioral significance. The behavioral urgency hypothesis predicts capture only by stimuli that indicate the potential need for immediate action. New objects, objects that move suddenly, and looming objects are all behaviorally urgent, and all strongly capture attention. Relative to these stimuli, receding objects and uniquely colored items are not as likely to require immediate action, and they do not strongly capture.

Although this explanation is appealing, some caveats exist. First, only the failure of receding objects to capture attention separates this hypothesis from the prediction that any dynamic event should capture. Ideally, the hypothesis could be verified by additional studies using other behaviorally urgent and behaviorally irrelevant dynamic events. For example, stimuli that loom directly toward an observer should capture more strongly than stimuli that loom toward a point beside the observer. ${ }^{5}$ To test this possibility, we have constructed search displays with multiple looming items - some looming directly at the observer, some simply moving in the plane of the monitor, and some doing both (i.e., looming toward a point beside the observer). We are currently exploring whether attention capture by a looming object requires that the object loom toward the observer. Furthermore, given that our looming and receding stimuli were implemented as size changes, ongoing studies are testing whether expansion is needed for capture by a looming stimulus or whether a change in depth could also produce capture (e.g., via binocular disparity), even in the absence of a size change.

Second, another recent result appears incompatible with the behavioral urgency hypothesis. Unlike the dynamic default and task-induced bias hypotheses, the behavioral urgency hypothesis might reasonably predict that luminance changes should not attract attention. Most published studies support this prediction (Enns et al., 2001; Yantis \& Hillstrom, 1994), but one recent study also found capture when letters abruptly changed in both contrast and contrast polarity (Enns et al., 2001). It is unclear that this event could be construed as behaviorally urgent. However, the urgency hypothesis might endure because a change in both contrast and contrast polarity often signals the appearance of a new object. When an abrupt onset occurs, there is a contrast change (zero to positive) as well as a contrast polarity change (zero to positive or negative, depending on whether the new object is lighter or darker than the background).
Finally, the predictions of the behavioral urgency hypothesis are not always as clear as they are in the case of looming and receding. For example, is a sudden oscillation (e.g., the jitter motion condition of Experiment 2) behaviorally urgent? One could claim so, because abrupt motion in general could signal the start of an urgent event (see Christ \& Abrams, 2002). However, by that argument, receding stimuli should also capture, since they also constitute abrupt motion. Furthermore, wind makes oscillatory movement ubiquitous, perhaps rendering capture by oscillatory motion an attentionally expensive false alarm. Except in the case of looming and receding objects, the behavioral urgency hypothesis was used to try to explain existing results rather than to predict new ones. It is possible to imagine a "behavioral urgency" account for most findings. Consequently, the strength of the hypothesis rests on its ability to predict capture in advance, as it did in the looming and receding case. We hope future research will put forward another clear test of the hypothesis.

The behavioral urgency hypothesis is similar to another recent explanation - the new feature hypothesis (Thomas $\&$ Luck, 2000). According to this account, attentional priority is governed by a salience or activation map that reflects both stimulus-driven and goal-directed activation (see, e.g., Wolfe, Cave, \& Franzel, 1989). This activation map sums the total salience of a stimulus over many feature dimensions. Some features carry more weight than others, and features can attain a high activation weight either by default or via current goal states. The new feature hypothesis is consistent with findings of capture by new objects and motion. The appearance of a new object captures attention because a new object introduces many new features at once, which leads to a high level of activation. Moving objects capture attention because transient activity is given a heavy activation weight in the central priority map. Note that this explanation of capture by moving objects belies a dangerous circularity in the new feature hypothesis: A feature dimension captures strongly if it creates a high level of activation, but activation levels can be determined only by capture strength (Thomas \& Luck, 2000). Therefore, the new feature hypothesis is consistent with almost any result; any property that captures attention can be said to have a high activation weight in the central priority map. However, because this hypothesis does make the specific prediction that multiple feature changes to old objects will capture more strongly than single feature changes, it is consistent with the finding that luminance contrast changes paired with contrast polarity changes strongly capture attention.

The behavioral urgency account is similar to the new feature account in that it makes only loosely specified predictions about what will capture. At its weakest, the behavioral urgency hypothesis is identical to the new feature hypothesis, with the addition that stimuli that are likely to signal behaviorally urgent events will have high activation weights in the central priority map. At its strongest, the behavioral urgency account predicts that only potentially 
behaviorally urgent events should attract attention. To tease apart the weak and strong versions of the behavioral urgency hypothesis, we are currently exploring whether a greater number of feature changes correlates with greater capture by using single, double, and triple feature changes to objects in a search task. The weak version predicts that more feature changes should lead to stronger capture, but the strong version predicts that feature changes should not capture unless they signal an urgent event.

The extensive literature on attention capture has focused largely on the issue of whether or not new objects are unique in their ability to capture attention. Given that other types of dynamic events capture as well, one interesting possibility is that moving, disoccluding, and looming objects actually capture attention in an even more strongly stimulusdriven manner than do abrupt onsets. Onsets capture attention when they are irrelevant to a search task, but their draw is still subject to top-down control (Folk et al., 1992; Yantis \& Jonides, 1990). Sudden motion, disocclusion, and looming stimuli might not be as constrained by task goals. Regardless of whether they capture completely independently of goal-directed processes, our results suggest that in the absence of other competing goals, a variety of dynamic events capture attention. With the possible exception of certain types of luminance changes (Enns et al., 2001), the events that capture (new objects, motion, looming) signal potentially behaviorally urgent stimuli, whereas nonurgent events (most luminance changes, receding, color singletons) do not attract attention.

\section{REFERENCES}

Christ, S. E., \& Abrams, R. A. (2002, November). Motion onset captures attention. Paper presented at the annual meeting of the Psychonomic Society, Kansas City, MO.

Enns, J. T., Austen, E. L., Di Lollo, V., Rauschenberger, R., \& YANTIS, S. (2001). New objects dominate luminance transients in attentional capture. Journal of Experimental Psychology: Human Perception \& Performance, 27, 1287-1302.

Folk, C. L., \& AnNetT, S. (1994). Do locally defined feature discontinuities capture attention? Perception \& Psychophysics, 56, 277-287.

Folk, C. L., Remington, R. W., \& Johnston, J. C. (1992). Involuntary covert orienting is contingent on attentional control settings. Journal of Experimental Psychology: Human Perception \& Performance, 18, 1030-1044.

Franconeri, S. L., Simons, D. J., \& Junge, J. A. (2003). Shifts of attention can be stimulus-driven. Manuscript submitted for publication.

Gellatly, A., Cole, G., \& Blurton, A. (1999). Do equiluminant object onsets capture visual attention? Journal of Experimental Psychology: Human Perception \& Performance, 25, 1609-1624.

Gibson, B. S., \& Kelsey, E. M. (1998). Stimulus-driven attentional capture is contingent on attentional set for displaywide visual features. Journal of Experimental Psychology: Human Perception \& Performance, 24, 699-706.

Gibson, J. J., Kaplan, G. A., Reynolds, H. N., JR., \& Wheeler, K. (1969). The change from visible to invisible: A study of optical transitions. Perception \& Psychophysics, 5, 113-116.

Hassenstein, B., \& Hustert, R. (1999). Hiding responses of locusts to approaching objects. Journal of Experimental Biology, 202, 1701-1710.

Hillstrom, A. P., \& Yantis, S. (1994). Visual motion and attentional capture. Perception \& Psychophysics, 55, 399-411.

JAMES, W. (1950). The principles of psychology. (Vol. 1). New York: Dover. (Original work published 1891)
Jonides, J., \& YANTIS, S. (1988). Uniqueness of abrupt visual onset in capturing attention. Perception \& Psychophysics, 43, 346-354.

Martin-Emerson, R. \& Kramer, A. F. (1997). Offset transients modulate attentional capture by sudden onsets. Perception \& Psychophysics, 59, 739-751.

Miller, J. (1989). The control of attention by abrupt visual onsets and offsets. Perception \& Psychophysics, 45, 567-571.

NÁÑEZ, J. S. (1988). Perception of impending collision in 3- to 6-weekold human infants. Infant Behavior \& Development, 11, 447-463.

Posner, M. I., Nissen, M. J., \& Ogden, W. C. (1978). Attended and unattended processing modes: The role of set for spatial location. In H. Pick \& E. Saltzman (Eds.), Modes of perceiving and processing information (pp. 137-157). Hillsdale, NJ: Erlbaum.

Rosenthal, R. \& Rosnow, R. L. (1991). Essentials of behavioral research: Methods and data analysis (2nd ed.). New York: McGraw-Hill.

TAKEUCHI, T. (1997). Visual search of expansion and contraction. Vision Research, 37, 2083-2090.

Theeuwes, J. (1990). Perceptual selectivity is task dependent: Evidence from selective search. Acta Psychologica, 74, 81-99.

Theeuwes, J. (1992). Perceptual selectivity for color and form. Perception \& Psychophysics, 51, 599-606.

Thomas, S. J., \& LUCK, S. J. (2000). Multiple pathways to the automatic capture of attention. Unpublished manuscript.

TodD, S., \& Kramer, A. F. (1994). Attentional misguidance in visual search. Perception \& Psychophysics, 56, 198-210.

Treisman, A. M., \& Gelade, G. (1980). A feature-integration theory of attention. Cognitive Psychology, 12, 97-136.

Turatto, M., \& Galfano, G. (2000). Color, form, and luminance capture attention in visual search. Vision Research, 40, 1639-1643.

Turatto, M., \& Galfano, G. (2001). Attentional capture by color without any relevant attentional set. Perception \& Psychophysics, 63, 286-297.

WANG, Y., \& Frost, B. J. (1992). Time to collision is signalled by neurons in the nucleus rotundus of pigeons. Nature, 356, 236-238.

Wolfe, J. M., CAVE, K. R., \& Franzel, S. L. (1989). Guided search: An alternative to the feature integration model for visual search. Journal of Experimental Psychology: Human Perception \& Performance, 15, 419-433.

YANTIS, S. (1993). Stimulus-driven attentional capture and attentional control settings. Journal of Experimental Psychology: Human Perception \& Performance, 19, 676-681.

YANTIS, S. (1996). Attentional capture in vision. In A. F. Kramer, M. G. H. Coles, \& G. D. Logan (Eds.), Converging operations in the study of visual selective attention (pp. 45-76). Washington, DC: American Psychological Association.

YANTIS, S., \& EGETH, H. E. (1999). On the distinction between visual salience and stimulus-driven attentional capture. Journal of Experimental Psychology: Human Perception \& Performance, 25, 661-676.

Yantis, S., \& Hillstrom, A. P. (1994). Stimulus-driven attentional capture: Evidence from equiluminant visual objects. Journal of Experimental Psychology: Human Perception \& Performance, 20, 95-107.

YANTIS, S., \& JonidES, J. (1984). Abrupt visual onsets and selective attention: Evidence from visual search. Journal of Experimental Psychology: Human Perception \& Performance, 10, 601-621.

YANTIS, S., \& JonidES, J. (1990). Abrupt visual onsets and selective attention: Voluntary versus automatic allocation. Journal of Experimental Psychology: Human Perception \& Performance, 16, 121-134.

\section{NOTES}

1. Whereas the dynamic default hypothesis posits a "default attentional control setting" for dynamic events (Folk et al., 1992), the new object hypothesis historically posits that new objects capture in a stimulusdriven manner when attention is in a "diffuse state" (Yantis, 1993). Aside from the type of event that captures, the difference between these two states is not clear. In both cases, some stimuli draw attention when other goals do not interfere. The only difference is that the new object hypothesis implies that separate neural or functional systems subserve stimulus-driven capture and goal-directed search. For the purposes of this report, both will be referred to as default attentional priorities. 
2. Note that the experiments in this article conform to this pattern. Across all experiments, when capture occurs, slopes are almost flat between set sizes 3 and 5 and are much steeper between set sizes 5 and 7 . An inspection of Figure 1 reveals that across the onset, disocclusion, looming, and the three motion conditions, the average valid cue slopes were far flatter between set sizes 3 and $5(M=6 \mathrm{msec} / \mathrm{item})$ than between set sizes 5 and $7[M=25.6 \mathrm{msec} /$ item; $t(5)=4.85, p<.005]$.

3 . Note that looming stimuli previously have been shown not to capture attention (Hillstrom \& Yantis, 1994). For the reasons discussed in Experiment 2, the displays used might have been suboptimal tests of capture.

4. If letters in a condition are larger, a larger luminance transient is created when the masks are removed. This larger transient could create more of an incentive for subjects to monitor for dynamic events, because a larger luminance transient is a better signal for the start of the search task. Therefore, the task-induced bias hypothesis could predict that conditions using larger letters will show stronger capture. To avoid a possible confound, letters in the final search displays of the receding condition were made slightly larger than the letters in search displays of the looming condition. Thus, the task-induced bias account predicts stronger capture by receding objects, but the behavioral urgency account predicts stronger capture by looming objects. Thanks to Chip Folk for pointing out the possibility of this confound.

5. Thanks to Anthony Norcia and John Anderson for this suggestion.

(Manuscript received October 29, 2001; revision accepted for publication February 14, 2003.) 